\title{
The prevalence of transfusion transmitted infections: A focus on hepatitis B virus among blood donors at Hawassa blood bank center, Southern Ethiopia
}

\author{
Fisseha Bonja, Mintewab Hussein, Jemal Alemu, \\ Daniel Gemechu, Misganaw Birhaneselassie
}

\begin{abstract}
Aims: Millions of lives are saved each year through blood transfusion but a safe blood supply is a critical component of health care to prevent the spread of blood-borne infectious diseases. Therefore, it is essential to assess the prevalence and identify the most common culprit and risk in transfusion services. Methods A cross-sectional study was conducted from April 2015 to May 2015 at the Hawassa blood bank center. Blood donors who donated blood for transfusion purposes were considered for the study. Whole blood was collected and serum was separated from each donor. The sera were used for examination of human immunodeficiency virus (HIV), hepatitis B virus (HBV), hepatitis C virus (HCV), and syphilis. Thick film was prepared and stained using Giemsa for malaria detection. Results: A total of $\mathbf{3 8 4}$ blood donors were screened during the study period. Among these donors, $67.2 \%(258)$ were males and $32.8 \%$ (126) were females. The overall prevalence of transfusion transmitted infections (TTI) was 28 out of $384(7.29 \%)$ apparently healthy donors. The seroprevalence of HIV, HBV, HCV, syphilis
\end{abstract}

Fisseha Bonja ${ }^{1}$, Mintewab Hussein ${ }^{1}$, Jemal Alemu ${ }^{1}$ Daniel Gemechu ${ }^{2}$, Misganaw Birhaneselassie ${ }^{2}$

Affiliations: ${ }^{1}$ Addis Ababa University, School of Laboratory Sciences, Addis Ababa, Ethiopia; ${ }^{2}$ Reach Ethiopia, Hawassa University, Department of Medical Laboratory Sciences, Hawassa, Ethiopia.

Corresponding Author: Misganaw -Birhaneselassie Mengesha, Hawassa University, Department of Medical Laboratory Sciences, Hawassa, Ethiopia; Email: misganawbs@googlemail.com

Received: 22 December 2016

Accepted: 28 February 2017

Published: 23 March 2017 and malaria was $6(1.6 \%), 16(4.2 \%), 2(0.5 \%)$, $3(0.8 \%)$ and $1(0.3 \%)$ respectively. Two out of $384(0.5 \%)$ had co-infections with HIV-HBV 1 (0.26\%) and HBV-HCV 1 (0.26\%). A 1:14 ratio (7.14\%) of the blood collected was discarded only due to the presence of TTI. The highest discard rate was recorded from $\mathrm{HBV}$ infected units $57.1 \%$, followed by HIV $21.40 \%$, syphilis $10.7 \%$, HCV $7.10 \%$, and malaria $3.60 \%$. Overall,

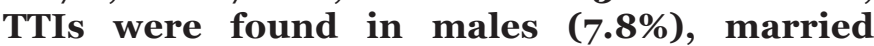
(2.5\%), rural (8\%), private/NGO employed donors (28.6\%), 45-54 age group (20\%), and in replacement/family donors $(16.1 \%)(p=$ o.039). Conclusion: The prevalence of TTIs in the Hawassa blood bank center was significantly high. HBV infection was the major cause for TTIs. Recommendations: Overall, effective clinical and laboratory screening of blood donors is essential. Proper treatment of TTI positive cases and a good donor selection program will help to reduce the prevalence of TTIs in donor units. Blood bank programs should give much more consideration in screening and diagnosis of HBV which is the main TTI that causes a high discard rate of blood.

Keywords: Hepatitis B virus, Southern Ethiopia, Transfusion transmitted infections, Volunteer donors

\section{How to cite this article}

Bonja F, Hussein M, Alemu J, Gemechu D, Birhaneselassie. The prevalence of transfusion transmitted infections: A focus on hepatitis B virus among blood donors at Hawassa blood bank center, Southern Ethiopia. Int $\mathrm{J}$ Blood Transfus Immunohematol 2017;7:7-14.

Article ID: 100029IJBTIFB2017 
$* * * * * * * * *$

doi:10.5348/ijbti-2017-29-OA-2

\section{INTRODUCTION}

Millions of lives are saved each year through blood transfusion but a safe blood supply is a critical component of health care to prevent the spread of blood-borne infectious diseases. Safe blood is a continuing concern especially in developing countries where $80 \%$ of the world's population lives [1].

Infectious diseases play a significant role in mortality and morbidity rates of individuals in developing countries, among these are transfusion transmitted infections (TTIs). As blood is a vehicle in the transmission of these infectious diseases, it can further contribute to the spread of these diseases in the community $[2,3]$.

In developed countries prevention of these TTIs has been achieved by reducing unnecessary transfusions, using only regularly-screened volunteer donors, excluding donors with specific risk factors and systematic screening of all donated blood for infection. By contrast, in many developing countries none of these interventions is applied uniformly and the risk of TTIs remains high [4-6].

Standard blood transfusion guidelines and protocols, including stringent donor screening, effective identification of blood-borne pathogens before donation, and proper counseling and treatment of positive cases, need to be implemented in the blood transfusion work process in Ethiopia [7].

Understanding the prevalence of TTIs and its associated factors, and identifying the most common TTIs are critical in the development of screening protocols and proper preventive measures in blood bank programs. Therefore, assessing the prevalence of TTIs and identifying common causes of TTIs in a blood bank service program may promote effective use of blood as a therapy. Therefore, this study aims to assess the prevalence of TTIs, and identify factors associated with safe blood provision in blood bank programs.

\section{MATERIALS AND METHODS}

A cross-sectional study was conducted from April 2015 to May 2015 at the Hawassa blood bank center. The study was conducted in SNNPRS, Ethiopia, Hawassa Regional Blood Bank Service Center. Yirgalem Hospital, which was established in 1968, previously served as the zonal blood bank center under the Ethiopian Red Cross Society. Currently, the Hawassa regional blood bank is serving as the center for blood bank activities for the SNNPR. Hawassa regional blood bank center is located in Hawassa city which is $275 \mathrm{~km}$ south of Addis Ababa (the capital city of Ethiopia) along the main road to Nairobi, Kenya. The blood bank mainly provides services for those hospitals that are found under Sidama zone, Gedio zone and Halaba special woreda.

Blood was collected from high school and college students, from family donation programs, and other volunteer donations in the community. Blood collected at the HBB Center are distributed to different hospitals and institutions as necessary.

Blood donors who donated blood for transfusion purposes were considered for the study. All donors were prospectively recruited. Volunteer blood was collected at satellite collection sites including high schools and colleges, and local community centers; replacement donations were collected at Hawassa Blood Bank Center. The blood donors were primarily screened for donor eligibility per the criteria set by NRCS (National Red Cross Society).

Whole blood was collected and serum was separated from each donor. The sera were used for examination of HIV, HBV, HCV, and syphilis. Thick film was prepared and stained using Giemsa for malaria detection. The testing procedures were performed by two experienced blood bank professionals, under the supervision of the Principal Investigator. All assays were performed following Standard Operating Procedures and Quality Control materials were used for all serological tests to maintain quality of data.

Sample size was calculated using the simple population proportion formula using the assumption that the proportion (P) of transfusion to be $50 \%, 95 \% \mathrm{CI}$, and marginal error (d) of $5 \%$ the sample size calculated was 384. Convenient sampling techniques were employed to take the first 384 blood donors who were eligible for donation based on a NRCS (National Red Cross Society) questionnaire to determine donor eligibility.

Data was entered Excel and exported to SPSS version 21 for analysis. Odds ratio and p-values were used to assess the strength of the association. The p-values less than 0.05 were considered as statistical significant at 95\% confidence interval. Ethical clearance was obtained from ethical review committee of Addis Ababa University College of Health Sciences, and permission to undertake the research was obtained from the SNNPRS Health Bureau.

\section{RESULTS}

A total of 384 blood donors were screened during the study period. These donors were $67.2 \%$ (258) males and $32.8 \%$ (126) were females with 2:1 ratio. The median age of the participants was 22 years (range 18-54 years). Most donors were in the 18-24 age group ( $\mathrm{N}=331,86.2 \%)$. From total donors, $91.9 \%(\mathrm{~N}=353)$ were voluntary and $8.1 \%(\mathrm{~N}=31)$ were family replacement donors (Table 1$)$. The $\mathrm{ABO}$ and $\mathrm{Rh}$ profile of the participants were $41.4 \%$ (N = 159) $\mathrm{O}, 31.5 \%(\mathrm{~N}=121) \mathrm{A}, 21.9 \%(\mathrm{~N}=84) \mathrm{B}, 5.2 \%(\mathrm{~N}=$ 
20) $\mathrm{AB}$, and 7.0\% $(\mathrm{N}=27)$ were $\mathrm{Rh}$ negative. In addition, many of the donors were above grade twelve $(\mathrm{N}=291$, $75.8 \%)$ and were students $(\mathrm{N}=330,85.9 \%)$ (Table 1$)$.

The overall prevalence of TTI was $7.29 \%(\mathrm{~N}=28)$. The seroprevalence of HIV, HBV, HCV, syphilis and malaria was $1.6 \%(\mathrm{~N}=6), 4.2 \%(\mathrm{~N}=16), 0.5 \%(\mathrm{~N}=2), 0.8 \%(\mathrm{~N}$ $=3)$, and $0.3 \%(\mathrm{~N}=1)$, respectively; $0.5 \%(\mathrm{~N}=2)$ had co-infections with HIV- HBV 1 (0.26\%) and HBV- HCV 1 (0.26\%). A 1:14 ratio (7.14\%) of the blood collected was discarded only due to the presence of a TTI. The highest discard rate was recorded from units infected with HBV $57.1 \%(\mathrm{~N}=16)$, followed by HIV $21.40 \%(\mathrm{~N}=6)$, syphilis $10.7 \%(\mathrm{~N}=3), \mathrm{HCV} 7.10 \%(\mathrm{~N}=2)$, and malaria $3.60 \%(\mathrm{~N}$ $=1$ ) as shown in (Figure 1).

Overall, TTIs were found in males $7.8 \%$ (20), married $12.5 \%$ (4), rural $8 \%$ (2), private/NGO (28.6\%) (2), the 45-54 age group 20\% (1), and in replacement/family donors $16.1 \%$ (5) [p = 0.039] (Table 2). This study showed that, although not statistically associated, HBV was more common in males 5\% (13), married 6.3\% (2), urban population $4.2 \%$ (15), the $18-24$ age group $4.5 \%$ (15), and in replacement donors $9.7 \%$ (3), which is different from the prevalence of HIV (Table 3). In addition, many of these study participants were volunteer donors, who mainly were males 67.5\% (232) [p $=0.039]$, unmarried 95.5\% (337), urban 96\%(339), students 92.4\% (326), above 12 grade $98.6 \%$ (287), and in the $18-24$ age group 91.8\% (324) [p = 0.001].

\section{DISCUSSION}

This study showed the prevalence of TTIs was 7.29\% (28 donor units). Comparable results were obtained in studies performed in Zambia (6.65\%) [8], Tanzania (8.8\%) [9], and Northwest Ethiopia (9.5\%) [10]. This number showed a lower prevalence compared with other studies done in Mozambique (18.7\%) [11], East Sudan (13\%) [12], Cameroon (13.7\%) [13], in Gondar Ethiopia (18.5\%) [14]. However, the present study showed the prevalence of TTIs was high compared with a study done in Nepal (1.7\%) [15] and in India (0.93\%) [16].

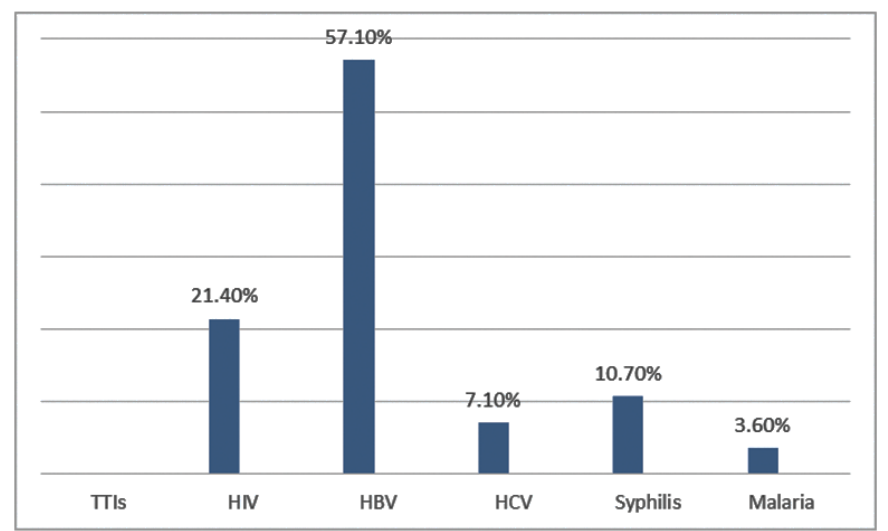

Figure 1: Discard rate of blood among blood donors due to TTIs at Hawassa Blood Bank Center.
Table 1: Socio-demographic characteristics of blood donors at Hawassa blood bank Center, Sidama zone, South Ethiopia April-May 2015.

\begin{tabular}{|c|c|c|}
\hline \multicolumn{2}{|l|}{ Characteristics } & \multirow{2}{*}{$\begin{array}{l}\mathbf{N}(\%) \\
331(86.2)\end{array}$} \\
\hline Age & $18-24$ & \\
\hline & $25-34$ & $41(10.7)$ \\
\hline & $35-44$ & $7(1.8)$ \\
\hline & $45-54$ & $5(1.3)$ \\
\hline & Total & 384 (100.0) \\
\hline \multirow[t]{3}{*}{ Sex } & Male & $258(67.2)$ \\
\hline & Female & $126(32.8)$ \\
\hline & Total & 384 (100.0) \\
\hline \multirow[t]{3}{*}{ Marital status } & Unmarried & $352(91.7)$ \\
\hline & Married & $32(8.3)$ \\
\hline & Total & 384 (100.o) \\
\hline \multirow[t]{7}{*}{ Occupation } & Government & $24(6.3)$ \\
\hline & Merchant & $7(1.8)$ \\
\hline & Farmer & $15(3.9)$ \\
\hline & Student & $330(85.9)$ \\
\hline & Unemployed & $1(0.3)$ \\
\hline & Private/NGO & $7(1.8)$ \\
\hline & Total & 384 (100.o) \\
\hline \multirow{6}{*}{$\begin{array}{l}\text { Educational } \\
\text { background }\end{array}$} & Illiterates & $4(1.0)$ \\
\hline & $1-4$ & $5(1.3)$ \\
\hline & $5^{-8}$ & $9(2.3)$ \\
\hline & $9-12$ & $75(19.5)$ \\
\hline & Above 12 grade & $291(75.8)$ \\
\hline & Total & 384 (100.0) \\
\hline \multirow[t]{3}{*}{ Donation type } & Volunteers & 353 (91.9) \\
\hline & Replacements & $31(8.1)$ \\
\hline & Total & $384(100.0)$ \\
\hline \multirow[t]{5}{*}{ ABO } & A & $121(31.5)$ \\
\hline & B & $84(21.9)$ \\
\hline & $\mathrm{AB}$ & $20(5.2)$ \\
\hline & $\mathrm{O}$ & $159(41.4)$ \\
\hline & Total & 384 (100.o) \\
\hline \multirow[t]{3}{*}{$\mathbf{R h}$} & Positive & 357 (93.0) \\
\hline & Negative & $27(7.0)$ \\
\hline & Total & 384 (100.0) \\
\hline
\end{tabular}

The prevalence/epidemiology of TTIs varies among countries and settings. The TTIs studied in this study showed higher prevalence compared with many other studies. Our study findings showed a higher prevalence of HIV when compared with other studies, including $0.12 \%$ in Nepal [15], 0.005\% in Italy [17], 0.03\% in China [18], 0.12\% in Pakistan [19], 0.074\% in India [16]. In 
Table 2: Association of overall TTIs with socio-demographic factors of blood donors at Hawassa blood bank center, April-May 2015

\begin{tabular}{|c|c|c|c|c|}
\hline \multicolumn{2}{|c|}{ Donor Characteristics } & \multirow{2}{*}{$\begin{array}{l}\text { TTIs Pos } \\
20(7.8 \%)\end{array}$} & \multirow{2}{*}{$\begin{array}{c}\text { OR 95\% CI } \\
1.681(0.658-4.295)\end{array}$} & \multirow{2}{*}{$\begin{array}{c}\text { p-value } \\
0.275\end{array}$} \\
\hline Sex & Male & & & \\
\hline & Female & $6(4.8 \%)$ & & \\
\hline \multirow[t]{2}{*}{ Marital status } & Unmarried & $22(6.3 \%)$ & $0.467(0.150-1.449)$ & 0.187 \\
\hline & Married & $4(12.5 \%)$ & & \\
\hline \multirow[t]{2}{*}{ Residence } & Rural & $2(8 \%)$ & $1.214(0.270-5.457)$ & 0.801 \\
\hline & Urban & $24(6.7 \%)$ & & \\
\hline \multirow[t]{6}{*}{ Occupation } & Government employee & $3(12.5 \%)$ & - & - \\
\hline & Merchant & o & $0.357(0.047-2.740)$ & 0.322 \\
\hline & Farmer & o & - & - \\
\hline & Student & $20(6.1 \%)$ & - & - \\
\hline & Unemployed & $1(100 \%)$ & $0.161(0.029-0.884)$ & 0.036 \\
\hline & Private/ NGO & $2(28.6 \%)$ & - & - \\
\hline \multirow[t]{5}{*}{ Education } & Illiterates & o & - & - \\
\hline & $1-4$ & o & - & - \\
\hline & $5^{-8}$ & o & - & - \\
\hline & $9-12$ & $8(10.7 \%)$ & $1.811\left(0.755^{-4.343)}\right.$ & 0.183 \\
\hline & above 12 grade & $18(6.2 \%)$ & - & - \\
\hline \multirow[t]{4}{*}{ Age (years) } & $18-24$ & $22(6.6 \%)$ & $0.285(0.031-2.658)$ & 0.270 \\
\hline & $25-34$ & $2(4.9 \%)$ & $0.205(0.015-2.794)$ & 0.235 \\
\hline & $35-44$ & $1(14 \cdot 3 \%)$ & $0.667(0.032-14.03)$ & 0.794 \\
\hline & $45^{-54}$ & $1(20 \%)$ & - & - \\
\hline \multirow[t]{2}{*}{ Donation type } & Volunteers & $21(5.9 \%)$ & $0.329(0.115-0.944)$ & 0.039 \\
\hline & Replacements & $5(16.1 \%)$ & & \\
\hline
\end{tabular}

addition, syphilis had higher prevalence when compared with studies done in India (0.09\%) [20], in Nepal (0.48\%) [15], Italy (0.031\%) [17], Pakistan (0.07\%) [19]. Similarly, the prevalence of HCV was higher than studies done in India (0.1\%) [1], and in Pakistan (0.07\%) [19]. A single malaria case $1 / 384$ (0.3\%) was identified in this study, which is a higher proportion when compared with another study done on the prevalence of malaria in India $0.037 \%$ [21]. However, low compared with others studies done in Islamabad, Pakistan 1.20\% [22] and 6/600 (1\%) in Northern part of Ethiopia [23].

In addition to this, this study identified malaria screening of blood donated for transfusion purposes should be an essential task of blood bank laboratories in the study area. This study included malaria screening as part of the study even though malaria is not included as a screening test in blood transfusion centers in the region. Southern Ethiopia is endemic for malaria. It is possible to screen donors in blood bank centers for malaria. Blood bank centers employ adequate numbers of personnel to perform required activities the BTS (Blood Transfusion Service) protocol request. Overall, these findings and comparisons show that testing donor units for TTIs is of concern for the betterment of blood transfusion programs in Ethiopia. As blood donors are sourced from the general population, there are different epidemiological variables that affect the prevalence of TTIs in a society, and hence the prevalence of TTIs varies in a country, from area to area. The discrepancy in results may be due to study design, study duration, seasonal variation and geographical differences of the study populations. This study further used a higher proportion of volunteer donors that might decrease the prevalence rates of TTIs from other studies.

Students often are available as a good source of volunteer donors. High schools and universities can be a large pool of volunteer donors that provide a ready resource on a year to year basis. The student population is primarily composed of unmarried, urban, > 12 years' grade level, 18-24 age groups, and is volunteers. As indicated in Table 2, this group is a source of donors found to show a lower prevalence of TTIs than donors with the highest prevalence of TTIs who are married, 9-12 grade, 45-54 years, and who are replacement donors. From this respect, students are good sources of blood more likely to be free of TTIs. Therefore, such volunteer groups who are comparatively free of TTIs should be identified and encouraged to participate in blood bank collections in Ethiopia to ensure sustainable volunteer donations for a continued safe blood supply. 


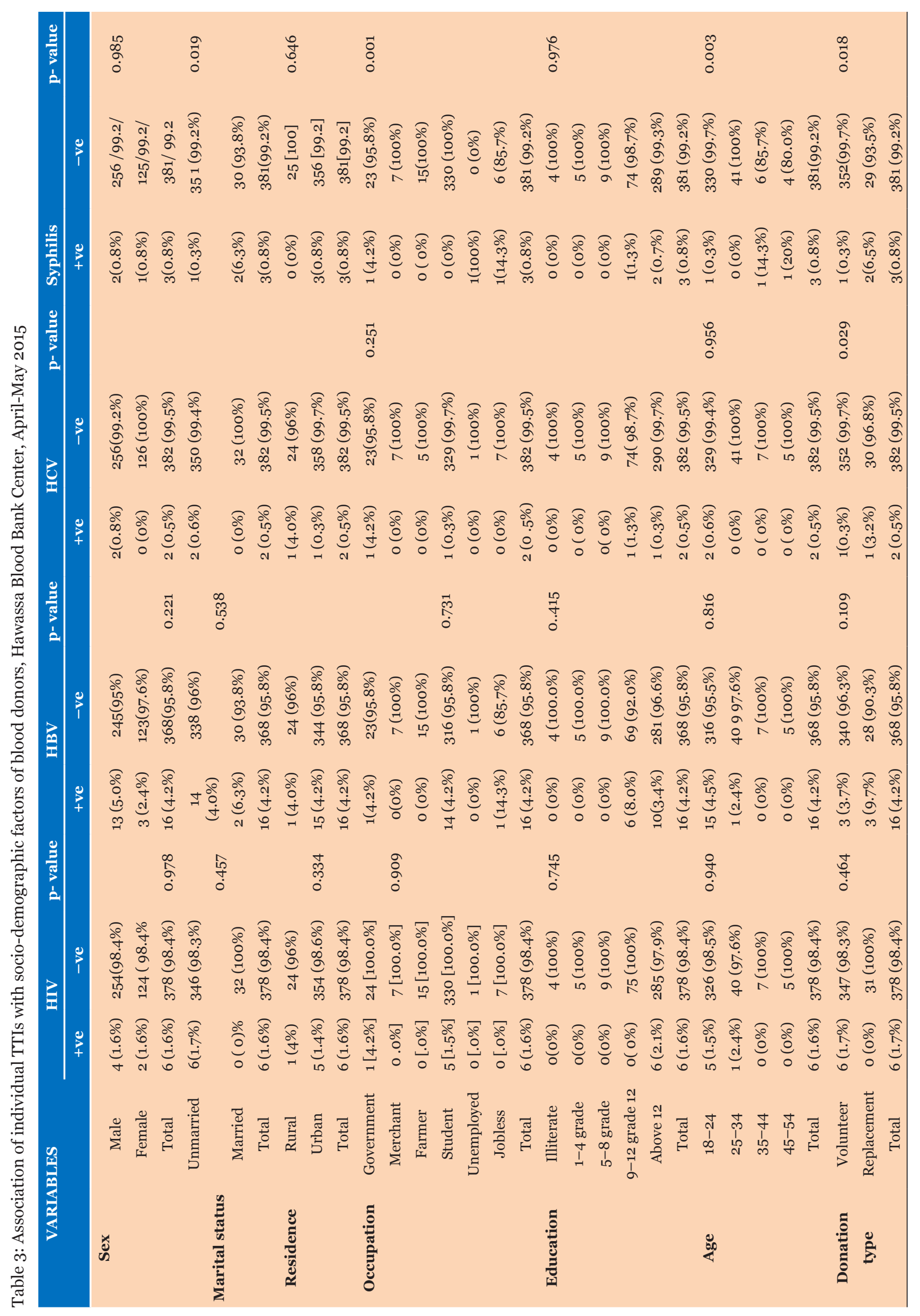


The seroprevalence of HBV infection was 4.2\% among blood donors in our study participants. This study finding showed a higher incidence compared with studies done in Egypt which was 2.3\% [24], 0.47\% in Nepal [15], 0.68\% in India [16] and $0.5 \%$ in Pakistan [19]. The seroprevalence of HBV infection in our study finding showed a lower prevalence when compared with studies done in Nigeria (11.1\%) [25], Tanzania (8.8\%) [9] Mozambique (10.6\%) [11] and Sudan (5.5\%) [12].

The prevalence of HBV in this study was higher than the prevalence of all the other TTIs combined. Moreover, the high discard rate of collected blood was due to more units infected with HBV. Indeed, $57.1 \%$ of the discard rate was associated with HBV, followed by HIV (21.4\%), HCV (7.1\%), syphilis (10.7\%) and malaria (3.6\%) (Figure 1). A 57\% rate of discard units due to HBV infection herein was consistent with other reports such as in Brazil with $52.5 \%$ of discarded blood units due to HBV seropositivity [26]; two additional studies indicated HBV reactivity that reached up to $54.8 \%$ [27] and $71.3 \%$ [28] of discarded blood units, confirming the high prevalence of this virus in Brazil [27].

The prevalence of HBV is higher than the combined frequency of other TTIs, as reported from studies in Nigeria [29], Eritrea [30], and other parts of Ethiopia [31] to mention a few; otherwise, HBV infection is often found higher than other TTIs in many studies, including those done in Tanzania [9] and Eastern Sudan [12], which also show a major discard rate of blood due to HBV infection. Data also show an alarming discard rate, primarily due to HBV reactivity in several central and West African countries [32].

Hepatitis B virus (HBV) is highly infectious and more prevalent than HIV. Screening donor units for HBV infection should be routinely performed in all blood transfusion services. The prevalence of HBV in the Ethiopian general population was reported to be between $6.1 \%$ and $7.4 \%$ in some studies [33, 34]. This shows there is a relatively lower prevalence rate of HBV in blood donors (4.2\%) than in the general population that demonstrates the effectiveness of donor education and strict donor selection and deferral criteria used by blood bank centers. However, this needs to be further reduced to safeguard the blood supply and to minimize waste of infected units. The cost of supplies, effort of professionals and blood as a resource contribute to the cost of a unit of blood. The major cost of a discarded unit of blood is due to the presence of a TTI as shown in this study. It is, therefore, essential to reduce the number of units found to be positive for a TTI in securing a cost effective and safe blood supply.

\section{CONCLUSION}

The prevalence of transfusion transmitted infections (TTIs) in a cross-sectional study conducted in the Hawassa blood bank center was shown to be significantly high. Hepatitis B virus (HBV) infection was the major cause of discard. Overall, effective clinical and laboratory screening of blood donors is critical. Blood bank programs should emphasize the importance of donor screening, particularly for identification of HBV infection, which remains the primary TTI that causes a high discard rate of donated blood.

$$
* * * * * * * * *
$$

\section{Acknowledgements}

We would like to express our gratitude to Addis Ababa University Graduate Studies for financial support of the research. We acknowledge Sidama Zone Health Department, Hawassa Blood Bank Center and the study participants for their cooperation. We also are indebted to Linda Fell and Sung Choi for reviewing the manuscript.

\section{Author Contributions}

Fisseha Bonja - Substantial contributions to conception and design, Acquisition of data, Analysis and interpretation of data, Drafting the article, Revising it critically for important intellectual content, Final approval of the version to be published

Mintewab Hussein - Analysis and interpretation of data, Revising it critically for important intellectual content, Final approval of the version to be published

Jemal Alemu - Analysis and interpretation of data, Revising it critically for important intellectual content, Final approval of the version to be published

Daniel Gemechu - Analysis and interpretation of data, Revising it critically for important intellectual content, Final approval of the version to be published

Misganaw Birhaneselassie - Analysis and interpretation of data, Revising it critically for important intellectual content, Final approval of the version to be published

\section{Guarantor}

The corresponding author is the guarantor of submission.

\section{Conflict of Interest}

Authors declare no conflict of interest.

\section{Copyright}

(C) 2017 Fisseha Bonja et al. This article is distributed under the terms of Creative Commons Attribution License which permits unrestricted use, distribution and reproduction in any medium provided the original author(s) and original publisher are properly credited. Please see the copyright policy on the journal website for more information.

\section{REFERENCES}

1. Bommanahalli BP, Javali R, Mallikarjuna Swamy CM, Gouda KU, Siddartha K, Shashikala KP. Seroprevalence of Hepatitis B and Hepatitis C viral 
infections among blood donors of central Karnataka, India. Int J Med Sci and Public Health 2014;3(3):2725 .

2. Ampofo W, Nii-Trebi N, Ansah J, et al. Prevalence of blood-borne infectious diseases in blood donors in Ghana. J Clin Microbiol 2002 Sep;40(9):3523-5.

3. Puoti M, Spinetti A, Ghezzi A, et al. Mortality for liver disease in patients with HIV infection: A cohort study. J AIDS 2000;24(3):211-7.

4. Glynn SA, Kleinman SH, Schreiber GB, et al. Trends in incidence and prevalence of major transfusiontransmissible viral infections in US blood donors, 1991 to 1996. Retrovirus Epidemiology Donor Study (REDS) JAMA 2000 Jul 12;284(2):229-35.

5. Arora D, Arora B, Khetarpal A. Seroprevalence of HIV, HBV, HCV and syphilis in blood donors in Southern Haryana. Indian J Pathol Microbiol 2010 Apr-Jun;53(2):308-9.

6. Hutin Y, Kitler ME, Dore GJ, et al. Global burden of disease (GBD) for hepatitis C. J Clin Pharmacol 2004;44(1):20-9.

7. Federal Democratic Republic of Ethiopia Ministry of Health. National Blood Transfusion Services Strategy. Addis Ababa, Ethiopia. February 2005. [Available at: http://ont.es/SiteCollectionDocuments/ afrlegethETH.pdf]

8. Mwambungu A, Siulapwa N, Mampi I. Seroprevalence of hepatitis $\mathrm{B}$ and $\mathrm{C}$ virus in blood donors at Lewanika General Hospital, Mongu, Western Province, Zambia. International Journal of Medical and Health Research 2015;1(1):80-4.

9. Matee MI, Magesa PM, Lyamuya EF. Seroprevalence of human immunodeficiency virus, hepatitis B and C viruses and syphilis infections among blood donors at the Muhimbili National Hospital in Dar es Salaam, Tanzania. BMC Public Health 2006 Jan 30;6:21.

10. Tessema B, Yismaw G, Kassu A, et al. Seroprevalence of HIV, HBV, HCV and syphilis infections among blood donors at Gondar University Teaching Hospital, Northwest Ethiopia: Declining trends over a period of five years. BMC Infect Dis 2010 May 10;10:111.

11. StokxJ,GilletP, DeWeggheleireA, etal.Seroprevalence of transfusion-transmissible infections and evaluation of the pre-donation screening performance at the Provincial Hospital of Tete, Mozambique. BMC Infect Dis 2011 May 23;11:141.

12. Tajeldin M. Abdallah, Abdel Aziem A. Ali. Seroprevalence of transfusion-transmissible infectious diseases among blood donors in Kassala, eastern Sudan. Journal of Medicine and Medical Science 2012:3(4):260-2.

13. Eboumbou Moukoko CE, Ngo Sack F, Essangui Same EG, Mbangue M, Lehman LG. HIV, HBV, HCV and T. pallidum infections among blood donors and Transfusion-related complications among recipients at the Laquintinie hospital in Douala, Cameroon. BMC Hematol 2014 Feb 12;14(1):5.

14. Diro E, Alemu S, G/Yohannes A. Blood safety \& prevalence of transfussion transmissible viral infections among donors at the Red Cross Blood Bank in Gondar University Hospital. Ethiop Med J 2008 Jan;46(1):7-13.

15. Shrestha AC, Ghimire P, Tiwari BR, Rajkarnikar M. Transfusion-transmissible infections among blood donors in Kathmandu, Nepal. J Infect Dev Ctries 2009 Dec 15;3(10):794-7.

16. Dhruva GA, Agravat AH, Dalsania JD, Katara AA, Dave RG. Transfusion transmitted diseases/ infections among blood donors in a tertiary care hospital at Rajkot, Gujrat, India. Int Res J Medical Sci 2014;2(4):16-9.

17. Drago F, Cogorno L, Ciccarese G, et al. Prevalence of syphilis among voluntary blood donors in Liguria region (Italy) from 2009 to 2013. Int J Infect Dis 2014 Nov;28:45-6.

18. Chen Y, Liu Z, Zhang Q, et al. Trend in prevalence of syphilis among voluntary blood donors in Xi'an, China from 2006 to 2010. Int J Infect Dis 2014 Feb;19:989.

19. Zulfikar A, Umaru N, Shreesha K. Seroprevalence of transfusion transmitted infection among blood donors in mangalore. J medica innovatica 2012;1(2):24-7.

20. Lathamani K, Bhaktha G, Nayak S, Kotigadde S. Prevalence of HIV, HCV, HBV and Syphilis in blood donors among the Dakshina Kannada District, India. Int J Curr Microbiol App Sci 2013;2(10):249-52.

21. Zou S, Stramer SL, Dodd RY. Donor testing and risk: Current prevalence, incidence, and residual risk of transfusion-transmissible agents in US allogeneic donations. Transfus Med Rev 2012 Apr;26(2):11928.

22. Waheed U, Khan H, Satti HS, Ansari MA, Malik MA, Zaheer HA. Prevalence of transfusion transmitted infections among blood donors of a teaching hospital in Islamabad. Ann Pak Inst Med Sci 2012;8(4):2369.

23. Gelaw B, Mengistu Y. The prevalence of HBV, HCV and malaria parasites among blood donors in Amhara and Tigray regional states. Ethiop J Health Dev 2008;22(1):1-5.

24. Nada HA, Atwa M. Seroprevalence of HBV, HCV, HIV and syphilis markers among blood donors at Suez Canal University Hospital Blood Bank in Egypt. J Blood Disorders Transf 2013;5:177-81.

25. Nwankwo E, Momodu I, Umar I, Musa B, Adeleke S. Seroprevalence of major blood-borne infections among blood donors in Kano, Nigeria. Turk J Med Sci 2012;42(2):337-41.

26. Borelli SD, Mazzola JC, Matta AC, Takemoto AY, Bértoli M. Blood discard rate and the prevalence of infectious and contagious diseases in blood donors from provincial towns of the state of Paraná, Brazil. Rev Bras Hematol Hemoter 2013;35(6):395-9.

27. Silva Rdo S, Ribeiro SA, Silveira RP, Freitas Mdos S. Evaluation of the sorologic pre-selection for the hepatitis B virus marker (total anti-HBc) in candidates to blood donation in the State of Acre, 2002.

[Article in Portuguese]. Rev Soc Bras Med Trop 2006 Mar-Apr;39(2):179-82.

28. Ramos VF, Ferraz FN. Perfil epidemiológico dos doadores de sangue do hemonúcleo de Campo Mourão-PR no ano de 2008. SaBios: Rev Saúde Biol 2010;5(2):14-21.

29. Buseri FI, Muhibi MA, Jeremiah ZA. Seroepidemiology of transfusion-transmissible infectious diseases among blood donors in Osogbo, south-west Nigeria. Blood Transfus 2009 Oct;7(4):293-9. 
30. Fessehaye N, Naik D, Fessehaye T. Transfusion transmitted infections: A retrospective analysis from the national blood transfusion service in Eritrea. Pan Afr Med J 2011;9:40.

31. Gelaw B, Mengistu Y. The prevalence of HBV, HCV and malaria parasites among blood donors in Amhara and Tigray regional states. Ethiop $\mathrm{J}$ Health Dev 2007;22(1):3-7.

32. Tapko JB, Mainuka P, Diarra-Nama AJ. Status of Blood Safety in the WHO African Region: Report of the 2006 survey. [Available at: www.afro.who.int]
33. Abebe A, Nokes DJ, Dejene A, Enquselassie F, Messele T, Cutts FT. Seroepidemiology of hepatitis $\mathrm{B}$ virus in Addis Ababa, Ethiopia: Transmission patterns and vaccine control. Epidemiol Infect 2003 Aug;131(1):757-70.

34. Erena AN, Tefera TB. Prevalence of hepatitis B surface antigen (HBsAg) and its risk factors among individuals visiting Goba General Hospital, South East Ethiopia, 2012. BMC Res Notes 2014 Nov 24;7:833.
Access full text article on other devices

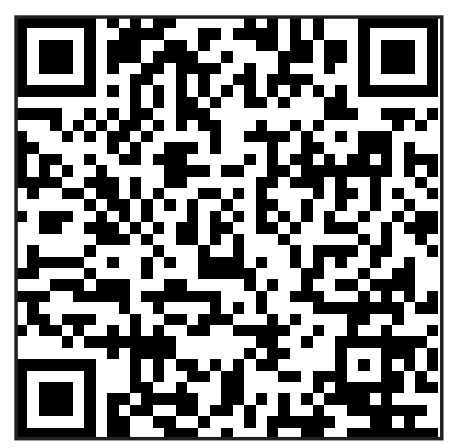

Access PDF of article on other devices

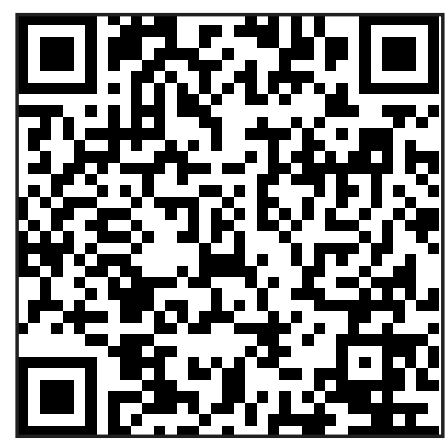

